\title{
INSERCIÓN LABORAL DEL ALUMNADO CON DISCAPACIDAD EN LA UNIVERSIDAD DE LAS PALMAS DE GRAN CANARIA (ULPGC)
}

\author{
Carmen Delia Díaz Bolaños \\ carmendelia.diaz@ulpgc.es \\ Universidad de Las Palmas de Gran Canaria \\ Celsa Cáceres Rodríguez \\ ccaceres@ull.edu.es \\ Universidad de La Laguna
}

\begin{abstract}
RESUMEN
El empleo es el eje vertebrador del desarrollo pleno en las sociedades actuales. Sin embargo, encontramos que las personas con discapacidad presentan dificultades de acceso al mercado laboral, incluso cuando han culminado con éxito estudios universitarios. Con el propósito de describir y analizar la situación de las personas con discapacidad que han egresado en la ULPGC entre 2000 y 2010, se han revisado las trayectorias laborales de 96 egresados mediante el emparejamiento de los registros de la universidad y los del Observatorio de Empleo de Canarias. Se han utilizado cuatro indicadores: inserción laboral, paro registrado, temporalidad y empleo encajado. Los resultados muestran que una de cada dos personas logra un empleo acorde a su formación al tercer año del egreso, lo que sugiere ciertos efectos positivos de la formación universitaria en la inserción laboral.
\end{abstract}

Palabras clave: discapacidad, universidad, inserción laboral, empleo encajado.

LABOUR INSERTION OF DISABLED STUDENTS AT

THE UNIVERSITY OF LAS PALMAS DE GRAN CANARIA

\begin{abstract}
Nowadays, to have a job is the best way to get a successful personal development. However, we find that people with disabilities have difficulties in accessing the labour market, even when they have successfully completed their university studies. This paper describes and analyzes the situation of people with disabilities who have graduated from the ULPGC between 2000 and 2010. The career trajectories of 96 graduates have been reviewed by matching the records from the ULPGC and those of The Canary Islands Observatory of Employment (OBECAN). Four indicators have been used: job placement, registered unemployment, temporary employment, and occupation. The results show that one in two people achieves a job according to their training in the third year after graduation, which suggests certain positive effects of university studies on job placement.
\end{abstract}

KeYwords: Disability, University, Job placement, Education-Job Match. 


\section{INTRODUCCIÓN}

El colectivo de personas con discapacidad es uno de los grupos que han sufrido una mayor exclusión social a lo largo del tiempo y que, a pesar de los avances en los modelos para explicar la discapacidad y las propuestas para una intervención eficaz, así como la existencia de normativa y recomendaciones internacionales basadas en el respeto de los derechos humanos y el principio de igualdad de oportunidades, sigue encontrándose en situación de desigualdad (Albor, 2019; Díaz-Velázquez, 2011; Huete García, 2013).

Esa discriminación se ha visibilizado en mayor medida en el sistema laboral, puesto que el empleo se configura como un generador de utilidad social y de responsabilidades sobre el que se construye nuestra imagen social y nuestro estatus, se considera la base para la estabilidad personal de todos los individuos; así, el empleo se ha considerado uno de los ejes vertebradores para el desarrollo pleno de las personas con discapacidad en el que se ha basado su inclusión social. De ahí que la falta de empleo se convierta en un factor que agrava la exclusión social, al limitar las oportunidades de la persona para adquirir las cotas de autonomía material y emocional que le permitirían desarrollarse como una persona adulta e independiente.

La Organización Internacional del Trabajo (OIT) entiende por «persona discapacitada toda persona cuyas posibilidades de obtener y conservar un empleo adecuado y de progresar en el mismo queden substancialmente reducidas a causa de una deficiencia de carácter físico o mental debidamente reconocida» (artículo 1.1) (OIT, 1983).

Las personas con discapacidad representan aproximadamente mil millones de personas, un 15\% de la población mundial (OMS, 2020), de las que alrededor del 80 por ciento están en edad de trabajar. Estas, en particular las mujeres con discapacidad, se enfrentan a barreras de distinta naturaleza que dificultan el disfrute en igualdad de oportunidades de un empleo. En comparación con la población sin discapacidad, las personas con discapacidad experimentan mayores tasas de desempleo e inactividad económica y están en mayor riesgo de pobreza y exclusión social (OIT, 2020).

La OIT (2001) destaca que el hecho de presentar una discapacidad tiene implicaciones distintas: mientras para unas personas la influencia en la capacidad para trabajar y participar en la sociedad puede ser prácticamente insignificante, para otras puede tener importantes repercusiones, por lo que se requerirán apoyos considerables, lo que pone en evidencia las múltiples variaciones que pueden darse entre estos extremos.

La inserción laboral de las personas con discapacidad ha estado presente dentro de los marcos de discusión de los diferentes organismos internacionales. En las últimas décadas se han articulado una serie de normativas y políticas sociales tendentes a la integración a través de la igualdad de oportunidades, la participación, la autodeterminación y la dignidad, todo ello auspiciado bajo el paradigma de los derechos humanos (Cabra de Luna, 2004).

A pesar del reconocimiento de los derechos y de las medidas que se han puesto en marcha para favorecer a las personas con discapacidad, siguen teniendo 
poca presencia en los empleos ordinarios, lo que pone de manifiesto que siguen existiendo dificultades para obtener, encontrar y mantener un puesto de trabajo (Pallisera et al., 2003). lo siguiente:

Con relación al empleo, la Organización Internacional del Trabajo plantea

El desarrollo viene con el empleo. Los empleos vinculan a las personas con la sociedad y la economía en las que viven. El acceso a un trabajo seguro, productivo y remunerado de manera justa -asalariado o por cuenta propia- es un factor fundamental para la autoestima de las personas y las familias, que les afirma su sentimiento de pertenencia a una comunidad, y les permite hacer una contribución productiva. El cambio hacia un desarrollo incluyente y sostenible no será posible si se niega a millones de personas la oportunidad de ganarse la vida en condiciones dignas y equitativas (OIT, 2015: 1).

Las personas con discapacidad reivindican el derecho a la participación social en condiciones de igualdad y, entre otros derechos, reclaman la inclusión educativa en todos los niveles de la educación formal y el acceso a empleos acordes a sus capacidades. El afán de la reivindicación de estos derechos tiene como fin último poder desarrollar plenamente su ciudadanía, asumiendo sus propias responsabilidades y contribuyendo activamente en todas las dimensiones de la sociedad en la que están inmersas.

De este marco general se desprende que la formación superior puede ser un medio para facilitar el acceso a mejores empleos; sin embargo, esta realidad ha sido escasamente estudiada. De ahí que nos propongamos estudiar la situación de los egresados con discapacidad de la Universidad de Las Palmas de Gran Canaria (ULPGC), concretamente tratamos de averiguar los efectos que la formación superior ha tenido en las trayectorias laborales de las personas con discapacidad que finalizaron sus estudios entre 2000 y 2010. Para ello, ha sido necesario diseñar una metodología específica que consiste en el emparejamiento de los registros académicos de la ULPGC con los datos disponibles en el Observatorio de Empleo de Canarias, de este modo se puede observar la evolución de los indicadores seleccionados a lo largo del tiempo y determinar la medida en que los empleos corresponden con el nivel de formación logrado.

En los siguientes apartados se presentan los principales antecedentes sobre la situación de las personas con discapacidad en el mercado laboral y en la universidad, así como los estudios previos relacionados con el tema.

\section{EL MERCADO LABORAL Y LAS PERSONAS CON DISCAPACIDAD}

La situación de discriminación y de exclusión en el ámbito laboral sigue siendo una realidad en nuestras sociedades.

Esta discriminación por falta de oportunidades viene dada inicialmente por elementos estructurales como el mercado de trabajo y su configuración, que en las 
últimas décadas se ha polarizado, generando un incremento de la competitividad y la segmentación entre los trabajadores, que tiende a marcar las diferencias entre los candidatos más y menos capacitados. Este último sector se ha incrementado desde mediados de los años ochenta, como lo atestigua el crecimiento combinado del paro. En este contexto hay que situar las elevadas tasas de inactividad, desempleo y paro de larga duración entre las personas con discapacidad, así como su mayor dificultad para acceder al mercado ordinario de trabajo en condiciones de estabilidad y promoción profesional (Colectivo IOÉ, 2003: 171).

Por otro lado, nos encontramos con elementos o características personales que presentan las personas con discapacidad. En general, tienden a pensar que carecen de potencialidades laborales y que, por tanto, han de depender económicamente de las políticas asistenciales, de ahí que el miedo a perder las prestaciones que perciben se convierta en un obstáculo singular para su acceso al empleo (Malo, 2004), a lo que se añade el desconocimiento de las fórmulas de entrada al mercado laboral. A esto se añaden elementos culturales como los estereotipos en relación con las personas con discapacidad, según los cuales los empleadores y la sociedad en general las consideren personas con escasas competencias para el desarrollo de una labor profesional (Malo et al., 2010).

La exclusión y la discriminación por razón de la discapacidad violan diversos derechos humanos universales, en particular el derecho a la igualdad.

La exclusión y la discriminación estructurales por motivo de discapacidad minan la competitividad de nuestros sistemas económicos y la cohesión de nuestros sistemas sociales. La sociedad en su conjunto se ve afectada cuando no se reconoce ni se facilita adecuadamente la expresión del talento y la realización del potencial que atesoran las personas con discapacidad (De Lorenzo, 2003: 78).

En los últimos decenios del siglo xx muchos países del mundo han modificado de forma apreciable sus marcos jurídicos y normativos en torno a la discapacidad, desarrollando políticas dirigidas a promover el derecho al trabajo de este colectivo, garantizando medidas de discriminación positiva, junto con legislaciones antidiscriminatorias o de equidad, tendentes a la inclusión de las personas con discapacidad.

Este es el caso de España, que, desde la creación de los Planes Nacionales de Empleo, los Planes de Acción para las Personas con Discapacidad y los Planes Nacionales para la Inclusión Social, ha centrado sus esfuerzos en la generación y la mejora continua de medidas dirigidas a optimizar la situación laboral de las personas con discapacidad. Sin embargo, a pesar de los cambios que se han producido, la realidad es testaruda y las tasas de actividad y de paro de las personas con discapacidad siguen siendo menores y mayores respectivamente que las de sus pares sin discapacidad.

En España, según los datos del Observatorio sobre Discapacidad y Mercado de Trabajo (ODISMET), en 2018 se contabilizaron 1899800 personas con discapacidad entre los 16 y los 64 años, lo que representa un 6,29\% del conjunto de la población española en edad de trabajar. La tasa de actividad se sitúa en el 34,4 \%, la tasa de empleo tan solo alcanza al $25,8 \%$, situándose la tasa de paro en el $25,2 \%$, de modo que solamente una de cada cuatro personas con discapacidad tiene un 
trabajo remunerado, evidenciándose así la compleja relación entre las personas con discapacidad y el empleo (ODISMET, 2020).

Mientras en la Comunidad Autónoma de Canarias, en 2017, la tasa de actividad de las personas con discapacidad se sitúa en el 30,1\% (43 puntos por debajo de la tasa de actividad de la población canaria sin discapacidad), la tasa de empleo es del 19,5\% (38,2 puntos menos que el conjunto de la población) y la tasa de paro alcanza el 35,2\% (11,8 puntos más que el resto de la población). Cabe añadir que las personas con discapacidad canarias presentan una de las tasas más bajas de participación en el mercado de trabajo y es donde existen mayores dificultades para su acceso al empleo (ODISMET, 2020).

Asimismo, existen evidencias empíricas que muestran que tanto el tipo de discapacidad como de deficiencia, junto con su gravedad, influyen en las probabilidades de ser activos (Cueto, Malo y Rodríguez, 2012; Malo, 2003, 2004). De forma específica, se ha demostrado que, entre todas las discapacidades, las relacionadas con la visión y la audición están asociadas a una mayor probabilidad de trabajar (Cueto, Malo y Rodríguez, 2012; Dávila, 2006; Malo, 2004). En cuanto al sexo, se observa que los hombres con discapacidad tienen más probabilidades de ser activos que las mujeres (Cueto, Malo y Rodríguez, 2012) y que las mujeres con discapacidad suelen tener mayores dificultades en el acceso a un empleo derivadas de la doble discriminación (Dávila, 2006).

En cuanto a la duración de los contratos, una de las consecuencias que ha presentado la crisis económica y el actual marco normativo laboral es el aumento de la temporalidad en el conjunto del mercado de trabajo, que ha crecido desde 2008, realidad y tendencia que también afecta a los contratos realizados por las personas con discapacidad, de forma que, en el 2012, la tasa de temporalidad de los contratos se encontraba en torno al 90\% (SEPE, 2013). Además, cabe señalar que la proporción de contratación indefinida en relación con la temporal es menor entre las personas con discapacidad sensorial y psíquica $(10,8 \%)$ que en el resto de los grupos (11,8\% discapacidad física, $12,3 \%$ sin discapacidad declarada y $13,4 \%$ discapacidad del lenguaje) (SEPE, 2009).

Por su parte, la Fundación ONCE y la Red Mundial de Empresas y Discapacidad de la OIT advierten que el mundo del trabajo se está reconfigurando, ello supone nuevas tendencias y desafíos, relacionados con las tecnologías, las competencias y los cambios cultural, demográfico y climático. Todo esto conlleva modificar la forma de abordaje del empleo de las personas con discapacidad. En ese sentido, se identifican cinco objetivos fundamentales para la inclusión de las personas con discapacidad en el futuro del trabajo:

1. Las nuevas formas de empleo deben incorporar la inclusión de la discapacidad.

2. El desarrollo de competencias y el aprendizaje continuo debe ser inclusivo.

3. Las nuevas infraestructuras, productos y servicios deben seguir los principios de diseño universal (lo cual significa que pueden ser accesibles, comprendidos y utilizados por todos).

4. Las tecnologías de asistencia deben estar disponibles y ser asequibles. 
5. Más medidas para incluir a las personas con discapacidad en las áreas en desarrollo y crecimiento de la economía (Fundación ONCE y ILO Business and Disability Network, 2019: 6).

De lo anterior se puede concluir, que aún queda mucho trabajo por hacer para conseguir que las cotas de participación laboral de las personas con discapacidad sean, al menos, las mismas que para la población sin discapacidad, en tanto que a las dificultades habituales se añadirán las derivadas de los cambios que se están produciendo en el mercado de trabajo.

\section{LA UNIVERSIDAD Y LA INSERCIÓN LABORAL DE LAS PERSONAS CON DISCAPACIDAD}

No cabe duda que el acceso al empleo de las personas con discapacidad va a estar condicionado por la calidad de la formación recibida, por el tiempo de estancia en el sistema educativo, por el entorno social y económico, además de por las circunstancias concretas del mercado laboral en cada momento.

Visto que a mayor nivel de formación alcanzado por las personas con discapacidad mayores probabilidades de acceder a la población activa (Cueto, Malo y Rodríguez, 2012), la necesidad de adaptación de los currículos universitarios a las demandas de la sociedad actual está fundamentada en la búsqueda de una formación universitaria más integral y social, no solo desde el punto de vista de los conocimientos, sino también desde el ámbito personal, humanístico, tecnológico y laboral.

A esto se puede responder dentro del Espacio Europeo de Educación Superior (EEES), que conllevó el diseño de las titulaciones a partir del modelo de competencias que los estudiantes universitarios deben adquirir en su proceso formativo para lograr un título académico. Este modelo educativo provoca que necesariamente se unifiquen los perfiles profesionales de cada titulación conforme a un procedimiento que garantice la transparencia, la homogeneidad y la calidad; ello obliga a las universidades a generar un marco educativo que facilite el aprendizaje a lo largo de toda la vida del alumnado, dotándolo de especialización en función de las demandas sociales, laborales y económicas de cada momento. Asimismo, supone la incorporación de modelos activos de aprendizaje que permitan mantener cierta sincronía entre el mundo universitario y el mundo laboral-profesional.

La incorporación de las universidades españolas al EEES exige desarrollar planes de calidad de sus títulos con el objeto de disponer de datos fiables sobre la adecuación sociolaboral de la formación impartida. En la práctica implica incorporar sistemas de seguimiento para conocer los resultados de la formación, entre otros, los datos de inserción laboral de los graduados y el grado de satisfacción con la formación recibida (ANECA, 2009).

Este nuevo elemento ha producido un cambio en la situación y en los últimos diez años son las universidades las que han ido generando sistemática y periódicamente datos sobre los procesos de inserción laboral, referidos bien al conjunto de las titulaciones de cada universidad o bien a titulaciones específicas. Para ahondar 
en este tema, también se han iniciado estudios sobre egresados y sobre las posibilidades de ajuste entre la oferta de la universidad y las demandas de las empresas; por tanto, se puede hablar de dos líneas de estudios: los que se centran en las necesidades o demandas del mercado de trabajo y los dedicados al análisis del itinerario de transición de la educación universitaria al empleo.

A día de hoy, el sistema universitario español elabora informes anuales sobre todos los aspectos seńalados. Los datos son publicados tanto por las universidades como por la ANECA; además, se difunden a través de encuentros técnicos, publicaciones y congresos. Dicho esto, se asume que el número de estudios es elevado; sin embargo, cabe destacar que en los mismos no se tenga en cuenta, o quizás resulte poco motivador, el análisis de los datos referidos al alumnado con discapacidad que se encuentran en las universidades españolas.

Así, la mayoría de los informes anuales no incluyen apartados específicos destinados al análisis de la situación de las personas con discapacidad, donde se evalúen la formación que se les oferta y los mecanismos de inserción laboral que se facilitan, así como sus resultados, a pesar de que esto debiera ser una prioridad al tratarse de un colectivo con mayores dificultades para la transición al mercado laboral.

\section{ESTUDIOS PREVIOS SOBRE LA SITUACIÓN DE LAS PERSONAS CON DISCAPACIDAD EN LA UNIVERSIDAD Y EN EL MERCADO LABORAL}

En España existen pocos estudios detallados que aporten datos globales sobre los titulados universitarios con discapacidad y su inserción laboral, que además incluyan información específica para las diferentes tipologías de discapacidad, lo que supone un hándicap a la hora de abordar la investigación sobre este tema.

Esta limitación, en parte, queda compensada por los estudios promovidos por algunas entidades relacionadas con la discapacidad y con otros desarrollados en marcos específicos. Se pueden distinguir tres grandes grupos: los promovidos por la Fundación Universia, los realizados desde el Observatorio Estatal de la Discapacidad (OED) y los que se han realizado de manera puntual respondiendo a demandas concretas.

- Estudios realizados por la Fundación Universia, con la colaboración del Comité Español de Representantes de Personas con Discapacidad (CERMI) y otras entidades.

Se trata de una serie de trabajos que analizan la situación de la discapacidad en el sistema universitario español. Se iniciaron en el curso 2011-2012 y se han seguido realizando bianualmente. En estos informes no se trata en profundidad el tema que nos ocupa, pues tan solo se habla de empleo e inserción laboral para el alumnado con discapacidad, cuando se hace referencia a la oferta de los servicios de atención a estudiantes con discapacidad que existen en las universidades participantes en cada uno de ellos. Asimismo, a partir del segundo informe se añade como objetivo analizar 
la evolución de la situación respecto al informe anterior. Se han realizado cuatro informes:

- Estudio sobre el grado de inclusión del sistema universitario español respecto de la realidad de la discapacidad. Universidad y Discapacidad (Fundación Universia y CERMI, 2012), referido a los datos del curso 2011-2012, en el que participaron 48 universidades.

- II Estudio sobre el grado de inclusión del sistema universitario español respecto de la realidad de la discapacidad (Fundación Universia y CERMI, 2014). En esta edición, además de las 59 universidades participaron 426 estudiantes con discapacidad; recoge los datos del curso 2013-2014 y la evolución respecto al anterior.

- III Estudio sobre el grado de inclusión del sistema universitario español respecto de la realidad de la discapacidad (Fundación Universia, 2016). En esta ocasión participaron 55 universidades y 526 estudiantes con discapacidad. Igual que el anterior, analiza la evolución de los indicadores medidos.

- IV Estudio sobre el grado de inclusión del sistema universitario español respecto de la realidad de la discapacidad (Fundación Universia, 2018). En la última edición disponible la participación alcanzó a 72 universidades y 1720 estudiantes con discapacidad.

Del conjunto de estos estudios, tomando los datos que se recogen en el IV Estudio Universidad y Discapacidad (Fundación Universia, 2018), se desprende que el 1,5\% del total de matriculados en las universidades participantes son estudiantes con discapacidad; asimismo, se percibe una variación respecto del primer informe (2012) del 0,4\% mientras la variación respecto del tercer informe (2016) es del -0,2\%. La mayor proporción cursa estudios en las universidades públicas (1,5\% frente a $1,2 \%$ en las privadas) y el $4,1 \%$ opta por la enseñanza no presencial.

En cuanto a las características personales, se puede afirmar que existe equilibrio entre hombres y mujeres ( $51 \%$ y $49 \%$ respectivamente), más de la mitad de las personas tiene una discapacidad física $(55,9 \%)$ y realizan estudios de Ciencias Sociales y Jurídicas (54,5\%), mientras solo 1 de cada 4 personas accedió por el cupo de reserva de plazas para personas con discapacidad que, a su vez, son quienes más adaptaciones curriculares han recibido.

Otro aspecto a destacar es que 6 de cada 10 universidades ofrecen una atención específica y especializada a los universitarios con discapacidad en materia de empleabilidad e inclusión laboral, a través de los servicios de atención a personas con discapacidad (4 de cada 10) o de otros servicios dirigidos al conjunto de estudiantes (2 de cada 10) (Fundación Universia, 2018).

Entre los programas y actuaciones de apoyo a la empleabilidad destacan las de orientación laboral y acompañamiento en la definición de objetivos profesionales; los programas de prácticas en empresas, a través de los que se comunican a los estudiantes las ofertas laborales recibidas, se derivan casos al servicio de empleo de la universidad y se lleva a cabo la coordinación de 
actuaciones. En algún caso, los servicios de atención al alumnado con discapacidad gestionan bolsas de trabajo específicas (Fundación Universia, 2018).

- Estudios realizados por el Observatorio Estatal de la Discapacidad (OED), sobre la situación general de la discapacidad en Espańa, conocidos como Informes Olivenza, coordinados por Agustín Jiménez Lara.

Su objetivo es ofrecer una panorámica general sobre la situación de la población con discapacidad en España a partir del análisis de diversas fuentes secundarias. Contiene una parte dedicada a la inclusión educativa, que recoge algunos datos sobre la población que cursa enseñanzas universitarias, y otro capítulo dedicado al mercado laboral ${ }^{1}$ que ofrece información sobre su vinculación con el empleo y que permite observar algunos de los resultados de los egresados universitarios.

Desde 2010 se publican estudios que proporcionan una actualización exhaustiva de la situación según el conjunto de indicadores seleccionados. En este momento hay siete informes disponibles (Observatorio Estatal de la Discapacidad, 2010; 2014; 2015; 2016; 2017; 2018; 2019)2 .

Tomando como referencia el último informe Olivenza, hay 89400 jóvenes con discapacidad entre los 16 y los 24 años, el 2,2\% sobre el total de jóvenes, de los que solo el 4,8\% han alcanzado estudios superiores, lo que dista de sus homólogos sin discapacidad en 8,3 puntos (13,1\%) (Observatorio Estatal de la Discapacidad, 2019: 436).

Entre las personas con discapacidad ocupadas en 2017, el 29,4\% tiene estudios universitarios (el 58,9\% solo tiene estudios de secundaria) (Observatorio Estatal de la Discapacidad, 2019: 356).

Según este estudio, el perfil de los universitarios con discapacidad son mujeres $(18,3 \%)$ de entre 25 y 44 años $(18,6 \%)$ que viven en áreas densamente pobladas $(20,0 \%)$ con discapacidad visual $(23,4 \%)$ y con un porcentaje de discapacidad legal reconocida entre el $33 \%$ y el $44 \%$ (21,9\%) (Observatorio Estatal de la Discapacidad, 2019: 394).

- El tercer grupo está integrado por estudios independientes que tienen distintos objetivos y metodologías, por lo que seguidamente se resumen.

- Informe sobre el desarrollo profesional de egresados y estudiantes con discapacidad en la Universidad Española a Distancia (UNED) (Rodríguez de Rivera, 2010), realizado en colaboración con la Fundación Mapfre. El propósito de este estudio fue analizar la situación de los

${ }^{1}$ Es una parte del informe que anualmente realiza el Observatorio de Discapacidad y Mercado de Trabajo (ODISMET).

${ }^{2}$ La mayoría se pueden encontrar en la página web del OED: https://www.observatoriodeladiscapacidad.info/category/documentos/observatorio/informe-olivenza-observatorio/. 
titulados y estudiantes con discapacidad en la UNED, de cara a la optimización de la gestión de la bolsa de empleo existente.

Sus resultados indican que más del $80 \%$ de la población de estudiantes y egresados con discapacidad tienen entre 40 y 50 años, predomina la discapacidad física, con un grado de discapacidad entre el 33 y el $45 \%$, aunque existe un tercio de egresados que poseen una discapacidad severa (mayor del 65\%). Los participantes estiman insuficientes los mecanismos de información existentes en la institución para facilitar la adecuada inclusión educativa y laboral. Existe un bajo índice de egresados buscando empleo, la mayoría se encontraban trabajando en la Administración pública. Respecto al ajuste del puesto de trabajo con la titulación cursada, algo más del $30 \%$ considera que es adecuado, mientras que más del $40 \%$ habla de un claro desajuste.

- Integración laboral de los universitarios españoles con discapacidad. Detección de las fortalezas y debilidades en el momento del acceso al mercado laboral español. Percepción de los universitarios y percepción de las empresas (Dalmau-Montalá et al., 2010), financiado por la Fundación Universia y elaborado desde la Universitat Ramón Llull. El objetivo de este estudio fue explorar los puntos fuertes y los puntos débiles detectados por los titulados universitarios españoles con discapacidad en su proceso de inserción en el mercado laboral ordinario, así como la experiencia y la opinión de las empresas sobre este tema. Una síntesis de este trabajo fue publicada con el título Formación universitaria e inserción laboral. Titulados españoles con discapacidad y competencias profesionalizadoras (Dalmau-Montalá et al., 2013). Se trata de un estudio de ámbito nacional en el que participaron 687 titulados universitarios con discapacidad y 77 estudiantes con discapacidad, 19 servicios de apoyo y 16 empresas. Sus resultados apuntan que los titulados universitarios con discapacidad, generalmente, no reciben en la universidad los apoyos adecuados para poder desarrollar, suficientemente, las competencias profesionales; las prácticas profesionalizadoras son una oportunidad para la inserción laboral de los titulados con discapacidad; la discapacidad prevalece por encima de la calidad del curriculum vitae en el momento del acceso al mercado laboral ordinario (Dalmau-Montalá et al., 2013).

- Estudio sectorial por comunidades autónomas de la accesibilidad del entorno universitario y su percepción (Guasch, 2010). Es un trabajo muy extenso cuyo objetivo principal es valorar la accesibilidad, en sentido amplio, de las universidades españolas. Incluye un capítulo sobre la percepción de los universitarios con discapacidad, y, entre otras muchas cuestiones, se les pregunta por la inserción laboral. Entre sus resultados cabe destacar que el $75 \%$ de las universidades participantes ofrecen servicios de inserción laboral específicos (Guasch, 2010: 131), pero solo el 7,5\% de los entrevistados han hecho uso de los servicios de apoyo a la inserción laboral que ofre- 
cen los servicios de apoyo a la discapacidad de las universidades (Guasch, 2010: 129), ya que, en general, el alumnado con discapacidad piensa que su integración laboral será más o menos normal (Guasch, 2010: 145).

- La integración laboral de universitarios con discapacidad (Fundación Adecco, Fundación Bancaja y Universitat de València, 2012). Se trata de un diagnóstico sobre la inserción laboral y la situación en la que se encontraban los universitarios con discapacidad titulados entre 2007 y 2011 en la Universidad de Valencia. Su objetivo fue el análisis y conocimiento de las herramientas, recursos y dificultades que encuentra este grupo de estudiantes en su inserción laboral. Los resultados principales indican que el perfil general se corresponde con un hombre de entre 22 y 36 años, con discapacidad física, que estudia una carrera de Ciencias Sociales (Magisterio [13\%], Psicología [10,6\%], Filología [8,4\%], Enfermería [6,5\%] y Derecho $[6,5 \%])$. En cuanto a la inserción laboral, un $62 \%$ de los titulados con discapacidad se encontraba trabajando (en 2012) y un $14,7 \%$ no había tenido nunca empleo. De los que lograron un empleo lo hicieron en educación y formación $(26,1 \%)$ y en sanidad y salud (20,7\%); así, si se tiene en cuenta que las dos carreras más estudiadas son Magisterio y Psicología, se podría concluir que la mayoría trabaja en un empleo relacionado con lo que ha estudiado.

- Discapacidad, Estudios Superiores y Mercado de trabajo. Barreras de acceso y repercusión en la inserción laboral (Red2Red Consultores, 2013)3. El objetivo de este estudio fue realizar un diagnóstico de la participación y acceso de las personas con discapacidad al sistema de enseñanzas superiores de régimen general (incluye la formación profesional de segundo ciclo), de los factores que generan desigualdad y discriminación en el acceso y continuidad en la realización de estos estudios y de las posibilidades de su posterior inclusión en el mercado laboral.

En términos generales, sus resultados apuntan una evolución positiva en el acceso a los estudios superiores por parte de las personas con discapacidad, si bien todavía persisten barreras y dificultades que estas tienen que superar tanto para acceder como para culminar estos estudios. Asimismo, se pone de manifiesto que las personas con discapacidad con estudios superiores aún siguen sin acceder en igualdad de condiciones, con el conjunto de la población activa, al mercado laboral, aunque sus posibilidades de inserción son mayores

\footnotetext{
3 Elaborado en el marco del Programa Operativo de Lucha contra la Discriminación 20072013 y cofinanciado por el Fondo Social Europeo.
} 
que las de aquellas que no tienen estudios superiores (Red2Red Consultores, 2013: 103-105).

Todos los trabajos comentados han facilitado información sobre la realidad de la discapacidad en las universidades que han permitido ir desarrollando acciones que promuevan la mejora de los niveles de inserción laboral del alumnado universitario con discapacidad en nuestro país. Para ello se han articulado medidas y servicios de orientación y apoyo a la inserción laboral, como la creación de bases de datos o de bolsas de empleo específicas, donde los empresarios tengan fácil acceso a los titulados universitarios. A estos se añaden las acciones de sensibilización social que allanan el terreno para derribar estereotipos que dificultan la inserción laboral.

Actualmente, la universidad, a pesar de los avatares en los que se ha visto inmersa, sigue siendo una institución con un claro papel social para contribuir a mejorar la calidad de vida de las personas con discapacidad a través de su inclusión en la formación superior. Los resultados que muestran los estudios revisados apuntan la necesidad de seguir trabajando desde las universidades para mejorar el acceso a los estudios superiores de las personas con discapacidad, fortalecer los servicios de apoyo durante los mismos y seguir perfeccionando los programas de apoyo a la transición universidad-empleo (ordinario y adecuado al nivel de estudios logrado) de quienes egresan y tienen una discapacidad.

Tal y como se avanzó al inicio, teniendo en cuenta que la formación universitaria puede contribuir a mejorar la posición de las personas con discapacidad en el mercado de trabajo y que los estudios detallados sobre la transición al empleo de personas universitarias con discapacidad son muy escasos, se estima pertinente realizar este estudio, que tiene como objetivo describir y analizar la situación en el mercado de trabajo de las personas con discapacidad que han egresado en la ULPGC entre 2000 y 2010, observando en primer lugar la situación laboral y en segundo lugar la calidad del empleo logrado.

\section{METODOLOGÍA}

Para describir la situación laboral de los egresados universitarios con discapacidad, se toman como referencia los indicadores habituales: empleo y paro registrado. Para estimar la calidad del empleo, se ha optado por la combinación de dos factores: la estabilidad en el empleo tomando como indicador de referencia la duración del contrato suscrito (Malo y Muñoz-Bullón, 2006) y el ajuste entre los estudios realizados y el puesto de trabajo ocupado o «empleo encajado", que se puede asimilar con el «emparejamiento ocupacional» (occupational matching) (Blázquez y Herrarte, 2011), si bien en este enfoque se toma como referencia la ocupación que figura en la demanda de empleo de cada persona. Ambas dimensiones se han analizado mediante la observación de las trayectorias laborales de los egresados con un seguimiento a largo plazo (tres, cinco o diez años desde el inicio de la búsqueda de empleo) (Aguilar, 2005), para lo que ha sido necesario llevar a cabo análisis indi- 
viduales que permitan el emparejamiento entre las características personales y la situación laboral a lo largo del tiempo.

Cabe añadir que entre los antecedentes disponibles no se han encontrado estudios que se basen en el análisis de las trayectorias laborales individuales y utilicen el empleo encajado como forma de estimación de la calidad del empleo logrado por los egresados universitarios con discapacidad.

Para el desarrollo de esta investigación se han utilizado dos fuentes de información primarias: la base de datos de registros académicos de la ULPGC ${ }^{4}$ y la base de datos Observatorio Canario del Empleo y la Formación Profesional (OBECAN) del Gobierno de Canarias ${ }^{5}$, accesibles al amparo del Protocolo de Intercambio de Datos Administrativos suscrito entre ambas instituciones.

Por consiguiente, para lograr el objetivo propuesto, se construyeron las trayectorias laborales emparejando los registros individuales de ambas bases de datos. Esto permite observar la adaptación al mercado laboral del alumnado de la ULPGC con algún tipo de discapacidad mediante el análisis de la situación laboral y de la calidad del empleo obtenido.

El análisis de la situación laboral se estima mediante la inserción laboral y la situación de desempleo. La primera se entiende que se ha producido cuando, dentro de un periodo determinado, el/la egresado/a ha obtenido un empleo por cuenta ajena y la segunda se observa a partir del paro registrado, entendido como el número de egresados que se encuentran registrados como demandantes de empleo en un momento dado.

La calidad del empleo busca conocer el ajuste entre las condiciones laborales reales y la formación universitaria recibida. Para ello se analiza el tipo de contrato según su duración (tiempo indefinido o duración determinada) y la ocupación reseñada en el mismo. Específicamente se trata de observar si el empleo logrado se puede considerar «empleo encajado», que se produce si la ocupación registrada en el contrato está dentro de las tres primeras categorías de la Clasificación Nacional de Ocupaciones (CNO).

En cuanto a la información sobre los estudios realizados, se ha seguido la clasificación utilizada por el observatorio de empleo de la ULPGC, que utiliza seis Grupos de Estudio: Enseñanzas Técnicas; Humanidades; Ciencias de la Salud; Empresariales, Económicas y Turismo; Ciencias Jurídicas; y, Educación y Deportes.

${ }^{4}$ Base de datos de registros académicos. Es la principal fuente de información, ya que ha permitido identificar al alumnado del curso académico 2010/11 que tenían algún tipo de discapacidad. Las principales variables utilizadas de este fichero son DNI, nacionalidad, tipo de discapacidad, año académico de matrícula, año académico de salida, código de estudio, tipo de ingreso a la universidad, municipio de procedencia, estudios de los padres, ocupación de los padres, grado de discapacidad reconocida.

5 Base de datos del Observatorio Canario del Empleo y la Formación Profesional (OBECAN), del Gobierno de Canarias. A través de esta base de datos se analiza y ofrece información sobre la evolución de las profesiones y del mercado de trabajo en la Comunidad Autónoma de Canarias. Para ello, toma los datos estadísticos elaborados por el Instituto Canario de Estadística y el Servicio Canario de Empleo. 


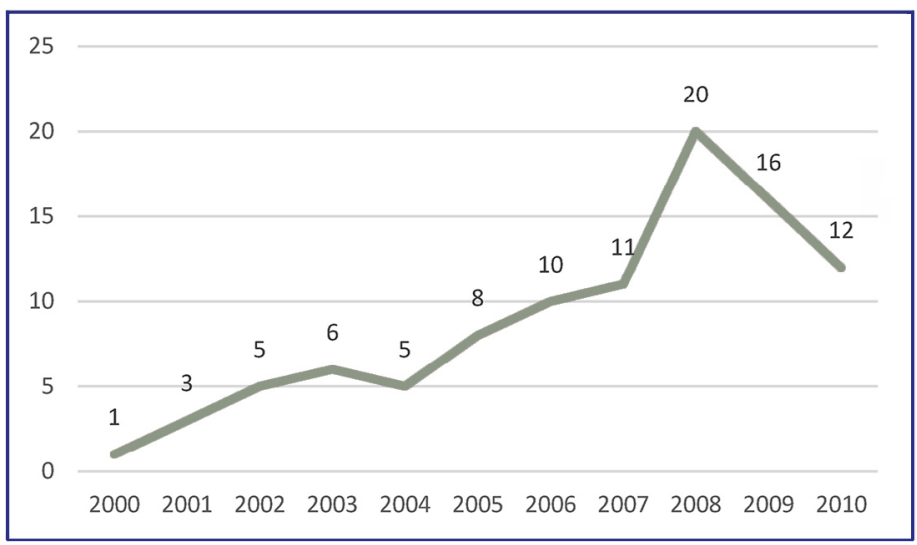

Fuente: elaboración propia a partir de los registros de la ULPGC.

Gráfico 1. Evolución del número de egresados con discapacidad por año.

Por tanto, las variables utilizadas han sido inserción laboral, paro registrado, tipo de contrato (duración) y ocupación (empleo encajado). Los datos de cada una de ellas se han agrupado por sexo, tipo de discapacidad y grupo de estudio.

Una vez seleccionados los datos ${ }^{6}$ correspondientes a las variables descritas, mediante el campo documento nacional de identidad (DNI) se procedió a emparejar los registros de ambas bases de datos (registros académicos y OBECAN). Esta combinación permite obtener las trayectorias laborales por cuenta ajena de los egresados de la ULPGC desde la finalización de sus estudios. Así, se puede conocer la evolución temporal (6 meses, 1, 2, 3 y 5 años desde el egreso) de la inserción laboral (empleo y paro registrado) y la calidad del empleo (tipo de contrato y ocupación-empleo encajado).

La muestra del estudio la componen las trayectorias laborales de 96 personas con discapacidad matriculadas en la ULPGC, cuyo egreso tuvo lugar entre el 2000 y el 2010, que suponen el 30,5\% del total de personas que aportaron el certificado de discapacidad en el momento de formalizar su ingreso en la universidad ${ }^{7}$.

Del total 49 eran mujeres $(50,3 \%)$ y 47 hombres $(49,7 \%)$; 9 con discapacidad auditiva $(9,2 \%), 68$ con discapacidad física $(71,4 \%), 3$ con discapacidad psíquica o intelectual $(3,1 \%)$ y 13 con discapacidad visual $(14,3 \%)$.

${ }^{6}$ Las bases de datos se trataron de acuerdo al compromiso de confidencialidad suscrito y las referencias a información personal fueron debidamente anonimizadas.

7 El total de personas con discapacidad matriculadas en la ULPGC, hasta el curso 20092010, que aportaron certificado de discapacidad fue de 314. En relación con el número medio de matriculados de la ULPCG para un curso académico, en torno a 20000 , esta población supone una proporción muy pequeña $(0,16 \%)$. 


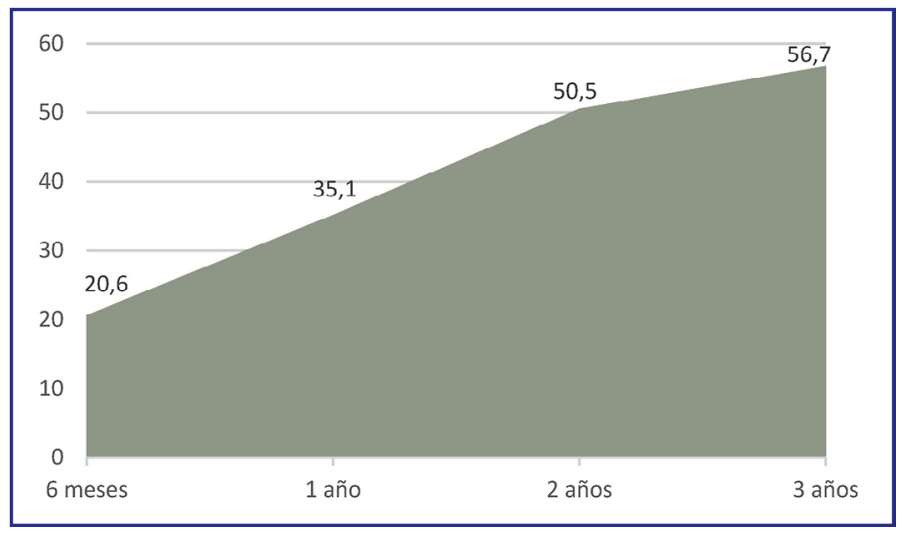

Fuente: elaboración propia.

Gráfico 2. Distribución temporal de la inserción laboral del alumnado con discapacidad egresado.

En cuanto a la distribución por grupos de estudio, 8 cursaron Humanidades (8,2\%), 56 Ciencias Sociales y Jurídicas (58,2\%), 15 Enseñanzas Técnicas (15,3\%) y 17 Ciencias de Salud (18,4\%). La media de permanencia en la universidad fue de 6,3 años (mujeres 5,7 y hombres 6,9). El 80\% egresaron a partir del 2005 (gráfico 1).

\section{RESULTADOS}

A continuación, se presentan los resultados para inserción laboral, paro registrado, tipo de contrato (duración) y empleo encajado (correspondencia entre ocupación del contrato y estudios finalizados). Primero se encuentran los datos globales y luego desagregados por discapacidad, sexo y grupo de estudio.

\section{INSERCIÓN LABORAL DE LOS EGRESADOS CON DISCAPACIDAD DE LA ULPGC}

El 20,5\% de los 96 egresados con discapacidad han obtenido un empleo a los seis meses, dentro de este grupo un $66,7 \%$ corresponde a las personas que tienen discapacidad psíquica o intelectual, seguido del $35,7 \%$ para el grupo con discapacidad visual, mientras que quienes presentan discapacidad auditiva apenas alcanzan el $11,1 \%$. De ahí que la diferencia entre el colectivo con mayor inserción y menor inserción sea de 55,5 puntos porcentuales (gráficos 2 y 3).

Según se puede observar en el gráfico 2 , el porcentaje de alumnos egresados con discapacidad que logran un empleo aumenta hasta el $56,7 \%$ a los tres años de haber egresado, si bien en ese momento el grupo con menor cota de contratación laboral corresponde a la discapacidad física, con un 50,7\%.

Por tanto, podemos decir que el nivel de inserción laboral global de este colectivo evoluciona positivamente a lo largo de los ańos, pues se pasa del 20,5\% 


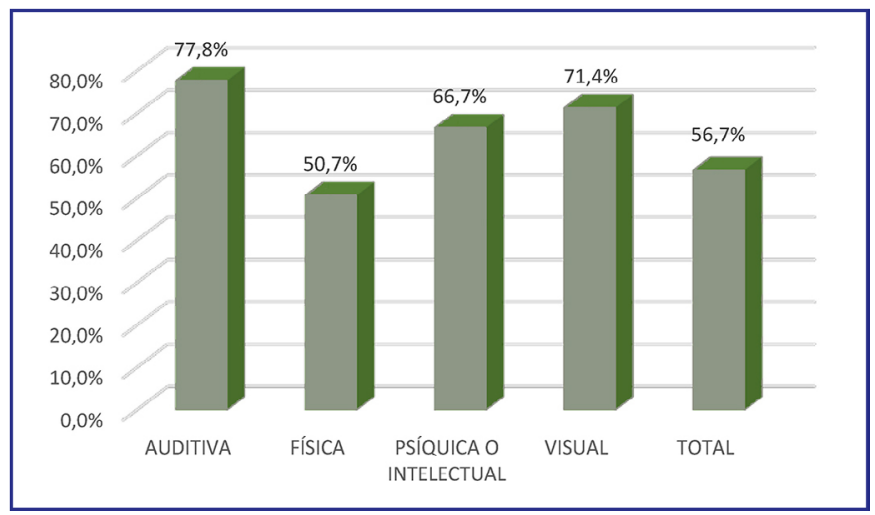

Fuente: elaboración propia.

Gráfico 3. Distribución de la inserción laboral según tipo de discapacidad a los 3 años.

a los seis meses hasta llegar al 56,7\% a los tres años, observándose un incremento significativo (15 puntos porcentuales) entre los dos primeros periodos.

Por tipos de discapacidad, se observa que el mayor índice de inserción $(77,8 \%)$ corresponde a las personas con discapacidad auditiva, seguidas de quienes tienen discapacidad visual $(71,4 \%)$. Mientras el grupo con menor cota de contratación es el grupo con discapacidad física (50,7\%) (gráfico 3).

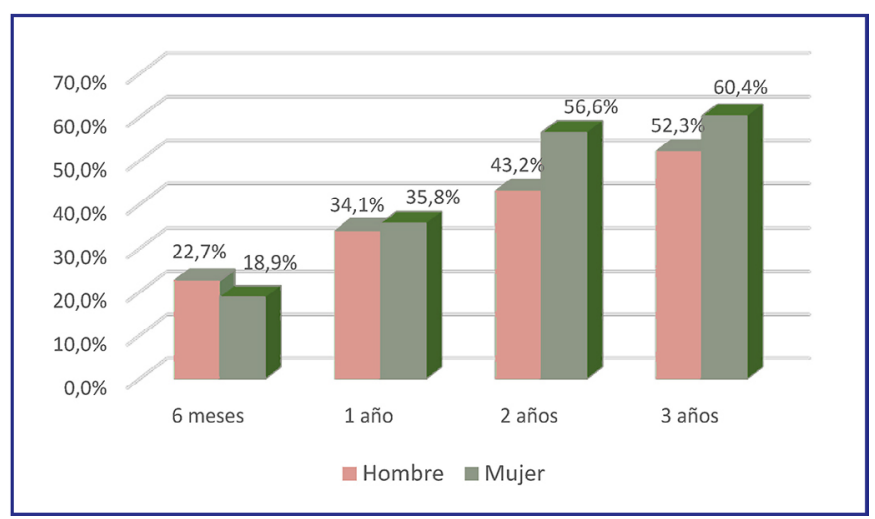

Fuente: elaboración propia.

Gráfico 4. Distribución de la inserción laboral del alumnado con discapacidad egresado según sexo.

En general, las mujeres presentan porcentajes de empleo sutilmente mayores que los de los hombres (gráfico 4), excepto en los empleos logrados en los primeros seis meses, donde se observa una diferencia de 3,8 puntos a favor de los hombres. 


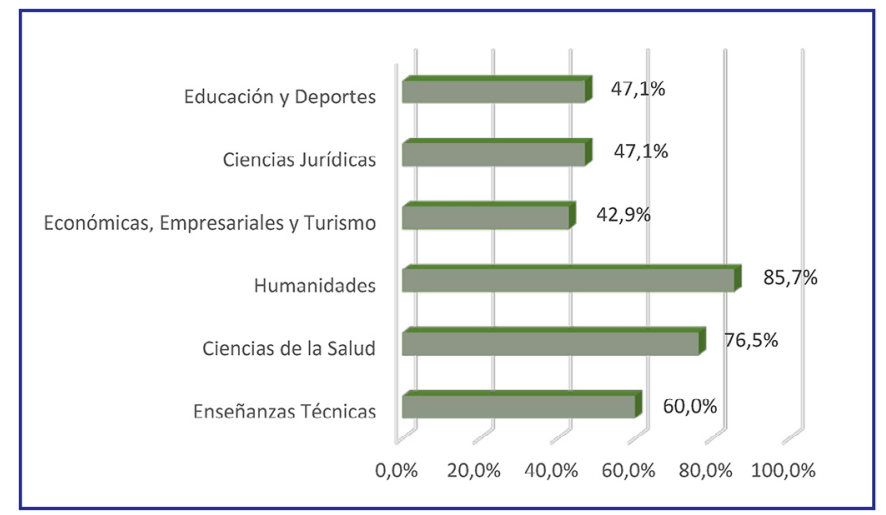

Fuente: elaboración propia.

Gráfico 5. Distribución de la inserción laboral del alumnado con discapacidad egresado según grupo de estudios a los 3 años.

Asimismo, cabe destacar que la mayor diferencia entre sexos se da en el segundo año, en el que las mujeres superan a los hombres en 13,4 puntos porcentuales.

En cuanto a los empleos logrados por grupos de estudios al tercer año de haber finalizado la formación universitaria, encontramos que la práctica totalidad $(85,7 \%)$ corresponde con quienes han cursado Humanidades, seguido por la formación en Ciencias de la Salud (76,5\%) y en Enseñanzas Técnicas (60\%). Mientras el alumnado con estudios de Económicas es el que presenta un menor nivel de inserción laboral (42,9\%) (gráfico 5).

En cuanto a la evolución temporal registrada por grupos de estudio, se observa un estancamiento del alumnado con estudios de Económicas y en Ciencias de la Salud, que presentan el mismo nivel en el segundo y el tercer año $(42,9 \%$ y $76,5 \%$ respectivamente). Por el contrario, el mayor incremento de incorporación al mercado laboral, entre el segundo y el tercer ańo, corresponde al grupo de Humanidades, cuya variación es de 14,3 puntos porcentuales.

Si se observa la evolución desde los seis meses a los tres ańos, los egresados que han cursado Enseñanzas Técnicas son el grupo con una mayor progresión en la inserción laboral, pues hay una diferencia de 46,7 puntos porcentuales entre ambos periodos.

\section{Paro Registrado de los egresados Con discapacidad de la ULPGC}

Como se indicó antes, como parte del análisis de la situación laboral se observa el paro registrado, que coincide con las personas que están inscritas como demandantes de empleo en el Servicio Canario de Empleo en los momentos observados durante el periodo de referencia.

Como se puede observar en el gráfico 6, el paro registrado en el alumnado con discapacidad egresado oscila entre el $22,3 \%$ a los seis meses y el $15,6 \%$ 


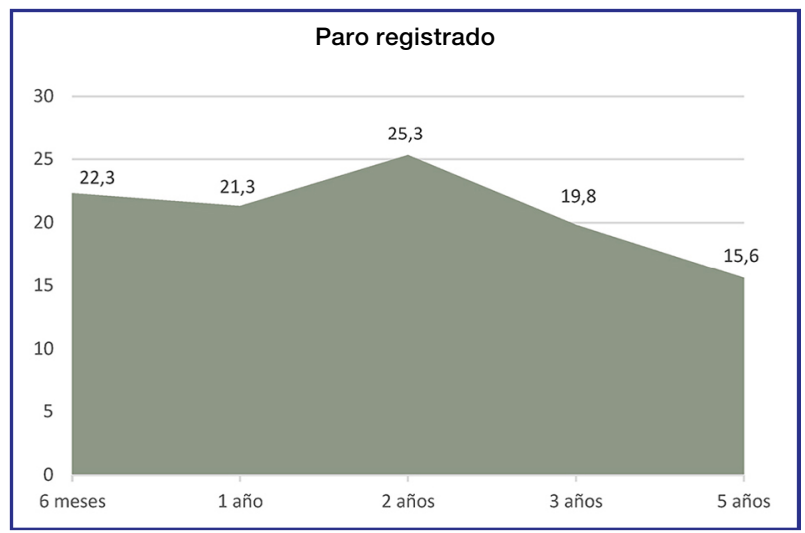

Fuente: elaboración propia.

Gráfico 6. Evolución temporal del paro registrado del alumnado con discapacidad egresado.

a los 5 años. Cabe señalar que es al segundo año del egreso cuando se registra el valor máximo $(25,3 \%)$, mientras al quinto ańo este se ha reducido en diez puntos porcentuales.

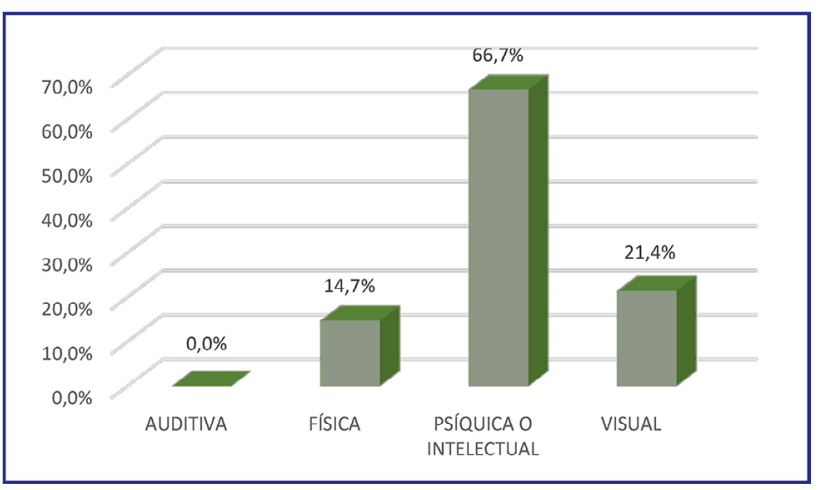

Fuente: elaboración propia.

Gráfico 7. Distribución del paro registrado del alumnado egresado según tipo de discapacidad a los 5 ańos.

Por tipo de discapacidad, encontramos que las personas con discapacidad auditiva pasan del 33,3\% de paro registrado a los seis meses al 37,5\% en el primer año para desaparecer al quinto año de haber terminado sus estudios. En el extremo opuesto se encuentran las personas con discapacidad intelectual, cuyo paro registrado al quinto ańo alcanza el $66,7 \%$, aunque a los seis meses no había ninguna persona registrada como demandante de empleo con este tipo de discapacidad (gráfico 7). 
Por tanto, entre las personas con discapacidad intelectual o psíquica es donde se observa el mayor incremento de paro registrado entre los seis meses y el año, que se incrementa en 50 puntos porcentuales, mientras para la visual aumenta 10 puntos y para la auditiva tan solo sube 4 puntos. Cabe añadir que el grupo personas con discapacidad física es el único que presenta un retroceso en el porcentaje de paro registrado, que se reduce en 5 puntos en ese periodo.

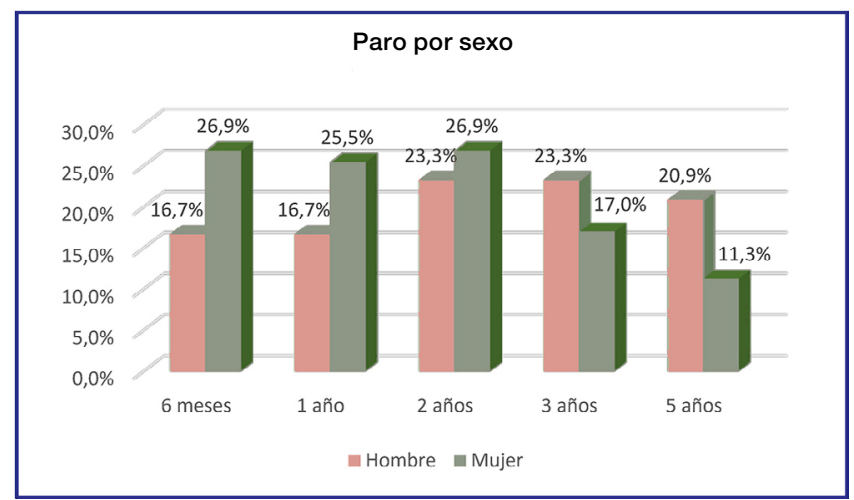

Fuente: elaboración propia.

Gráfico 8. Evolución temporal del paro registrado del alumnado egresado según sexo.

En el gráfico 8, se observa que el paro registrado entre las mujeres es mayor que entre los hombres hasta el segundo año, invirtiéndose a partir del tercer año, donde los hombres tienen porcentajes mayores de paro. Cabe destacar que mientras el paro femenino se reduce en torno a 15 puntos porcentuales al quinto ańo, el masculino aumenta solo 4 puntos.

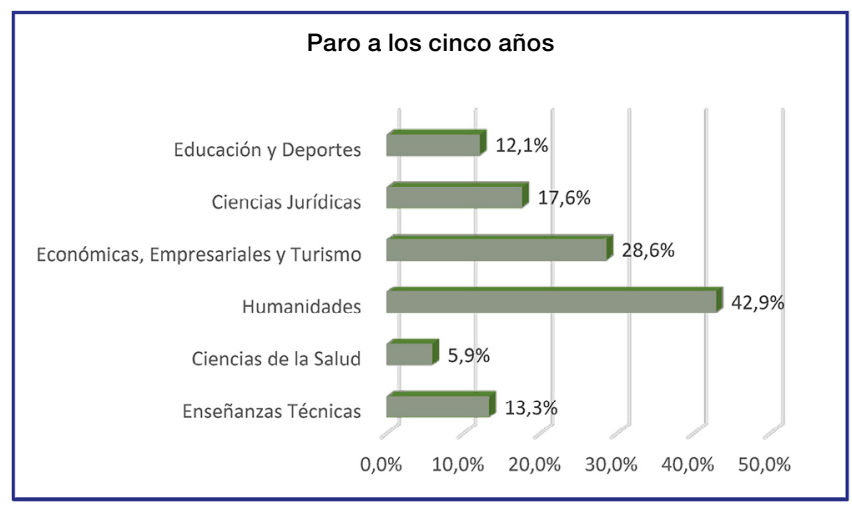

Fuente: elaboración propia.

Gráfico 9. Evolución del paro registrado del alumnado egresado según grupo de estudios a los 5 años. 
Como se puede observar en el gráfico 9, el mayor porcentaje de paro registrado al quinto año de haber finalizado los estudios corresponde a los estudios de Humanidades (40\%), seguido de los estudios de Económicas y Empresariales (28\%). Mientras el menor índice de paro corresponde al grupo de Ciencias de la Salud (7\%).

Respecto a la evolución en el tiempo, es igualmente en los estudios de Humanidades en los que se observa un mayor incremento del paro, 14 puntos en relación con los periodos anteriores; le sigue el grupo de Económicas y Empresariales, que duplica su tasa de paro. El resto de los grupos desarrollan una tendencia a la baja, mientras el de Ciencias Jurídicas permanece estable en todo el periodo.

\section{Tipo DE CONTRATO DE LOS EGRESADOS CON DISCAPACIDAD DE LA ULPGC}

El tipo de contrato que prevalece durante todo el periodo analizado es el de duración determinada, que se encuentra por encima del 75,5\% de los casos, frente al contrato indefinido, que se encuentra por debajo del $20 \%$.

En el gráfico 10 se puede observar que mientras los contratos temporales se reducen 15 puntos porcentuales entre su máximo nivel a los seis meses $(95,0 \%)$ y el más bajo en el segundo año $(75,5 \%)$, los contratos indefinidos se incrementan en la misma medida (pasan del 5\% a 24,5\%). Al tercer ańo del egreso sigue siendo mucho mayor la proporción de contratos temporales (80\%) que la de indefinidos (20\%), lo que parece reflejar la alta temporalidad del mercado de trabajo español.

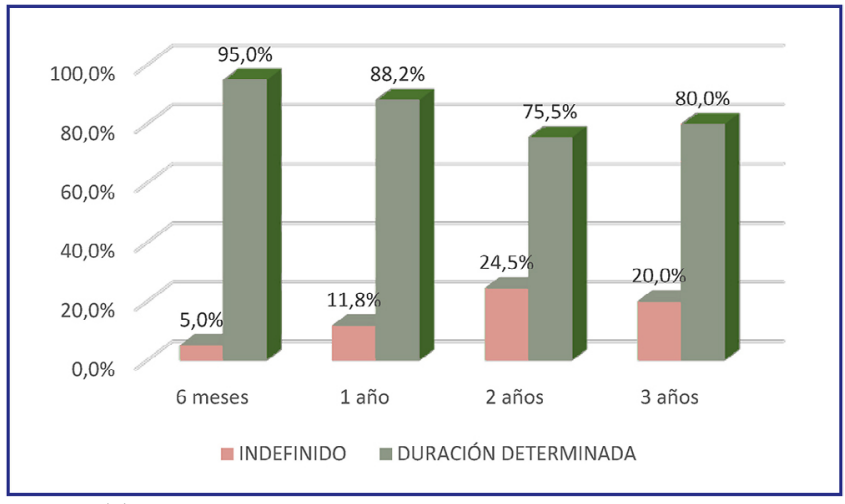

Fuente: elaboración propia.

Gráfico 10. Evolución por duración del contrato suscrito por los egresados con discapacidad.

Respecto al tipo de discapacidad, en el caso de la psíquica o intelectual la contratación temporal alcanza el 100\% de los casos y se mantiene constante durante todo el periodo analizado, siendo este grupo el que presenta el mayor nivel de temporalidad en el empleo y, por lo tanto, la mayor inestabilidad laboral, en comparación 


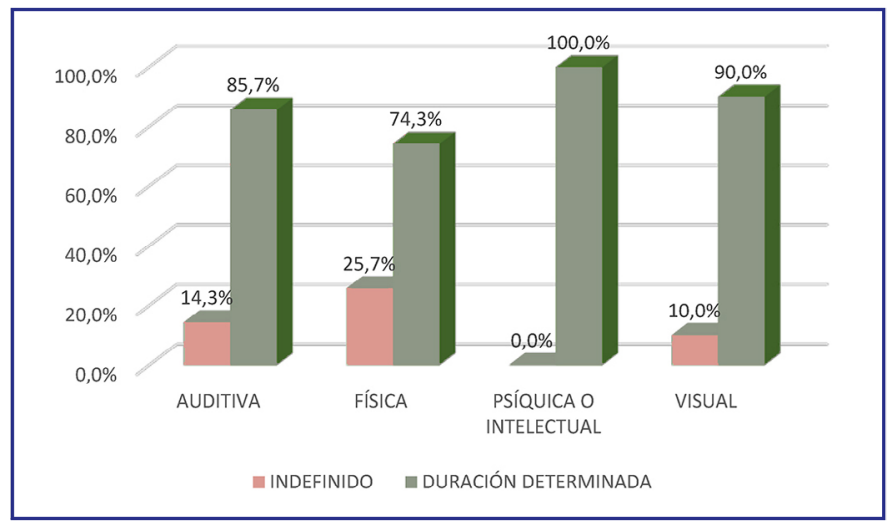

Fuente: elaboración propia.

Gráfico 11. Distribución de la duración del contrato suscrito según tipo de discapacidad al tercer año.

con el resto de tipos de discapacidad (gráfico 11). Cabe mencionar que, en el caso de las personas con discapacidad física, al menos 1 de cada 4 contratos es indefinido.

En relación con la contratación por sexos, los contratos temporales son mayores entre las mujeres, mientras que la contratación indefinida es mayor en los hombres, en todos los momentos del análisis (gráfico 12).

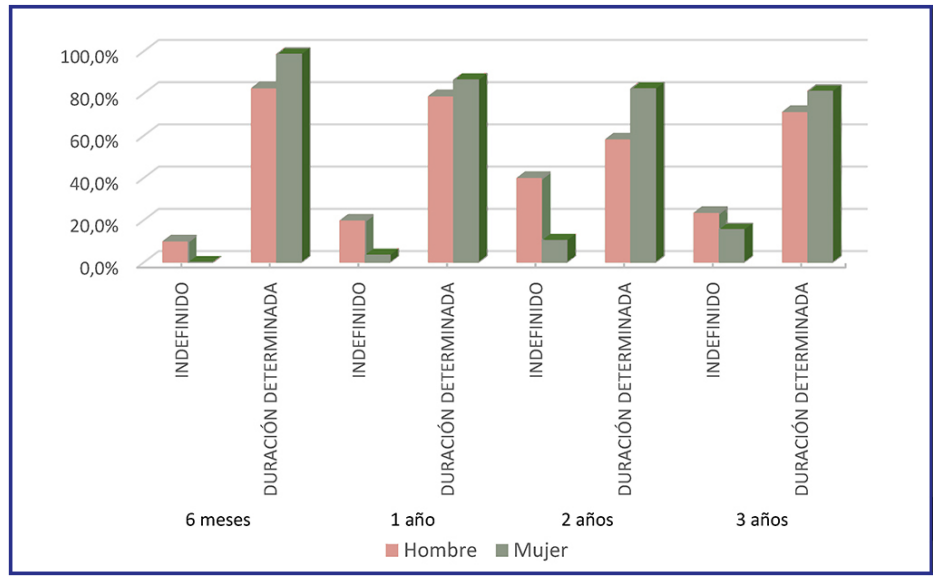

Fuente: elaboración propia.

Gráfico 12. Evolución temporal de la duración del contrato según sexo de los egresados con discapacidad.

El análisis por grupos de estudios igualmente refleja la temporalidad del mercado de trabajo español. En este caso, los contratos indefinidos presentan la 


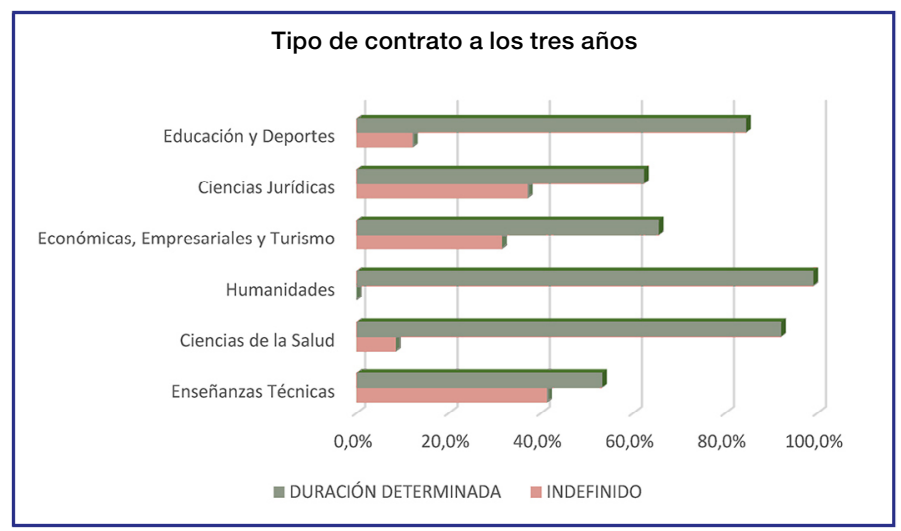

Fuente: elaboración propia.

Gráfico 13. Distribución de la duración del contrato suscrito según grupo de estudios a los 3 años.

mayor proporción entre los egresados de las Enseñanzas Técnicas, al contrario que en Humanidades, donde no existe ninguna contratación indefinida (gráfico 13).

EMPleo enCAJAdo de los Egresados CON DisCAPACIDAD dE LA ULPGC

Como se puede observar en el gráfico 14, el empleo encajado se mantiene estable durante prácticamente todo el tiempo analizado. Alcanza su mayor cota $(55,9 \%)$ el primer año y la menor al tercer año $(50,9 \%)$.

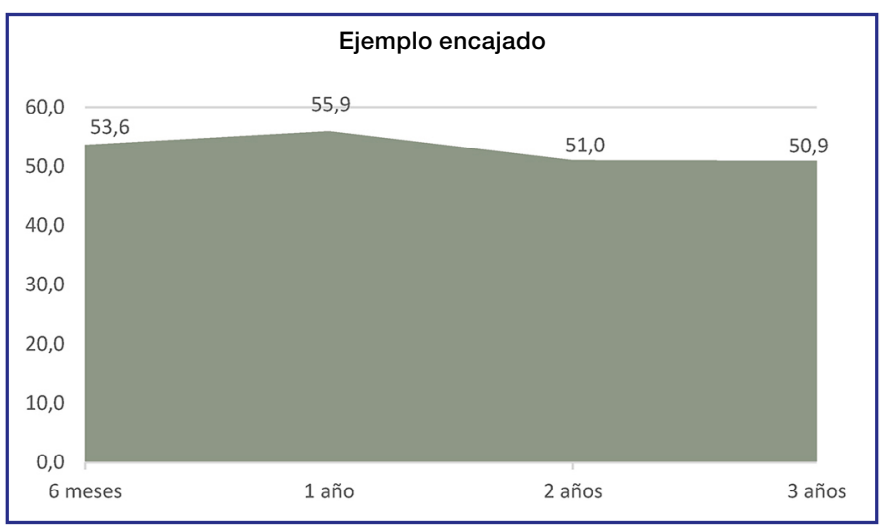

Fuente: elaboración propia.

Gráfico 14. Distribución temporal del empleo encajado del alumnado con discapacidad egresado. 
En conjunto el mayor porcentaje de empleo encajado al tercer año lo registra el grupo de personas con discapacidad visual $(70 \%)$ y el menor se observa en el de discapacidad física (45,7\%) (gráfico 15).

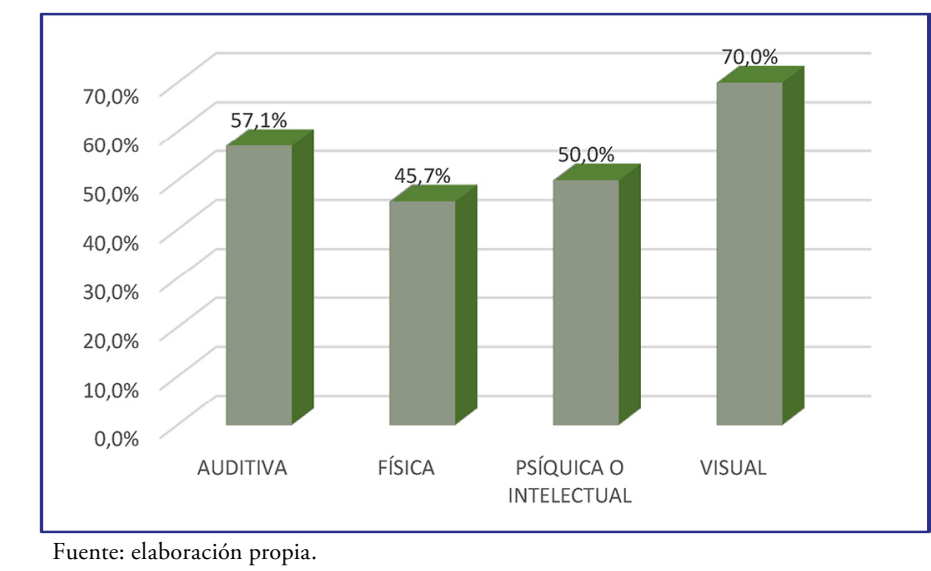

Gráfico 15. Distribución del empleo encajado del alumnado con discapacidad egresado según el tipo de discapacidad a los 3 años.

El análisis de la evolución temporal del empleo encajado por tipos de discapacidad muestra que a los seis meses es la discapacidad visual la que presenta el mayor porcentaje, un $80,0 \%$, mientras que el resto de las discapacidades se sitúan en torno al 50,0\%. Al cabo de un ańo, se produce un crecimiento principalmente entre las personas con discapacidad visual, situándose en el 85,7\%, seguidas de la discapacidad auditiva, cuyo empleo encajado alcanza el 66,7\%.

$\mathrm{Al}$ segundo año de inserción laboral se produce un estancamiento de la discapacidad intelectual en el 50\% y una caída generalizada del empleo encajado en todos los tipos de discapacidad. En el tercer año, nos encontramos con que la discapacidad intelectual y la auditiva sigue en los mismos parámetros del 50\% y el 57,1\% de empleo encajado, mientras que, en la discapacidad visual se observa una caída de 5 puntos. Por su parte, la discapacidad física es la única que experimenta un ligero aumento, 0,5 puntos, con respecto al ańo anterior.

Por sexos, se observan porcentajes mayores de empleo encajado entre los hombres, si bien esta proporción desciende en 23 puntos porcentuales a lo largo del tiempo. Por el contrario, entre las mujeres se observa la tendencia contraria, pues aumenta en 13 puntos el empleo encajado entre los seis primeros meses y el tercer año (gráfico 16). En conjunto, se observa que las diferencias por sexos en el empleo encajado tienden a desaparecer a lo largo del tiempo.

Para terminar, se muestran los resultados de empleo encajado por grupos de estudio, que, según se puede observar en el gráfico 17, a los tres años de la contra- 


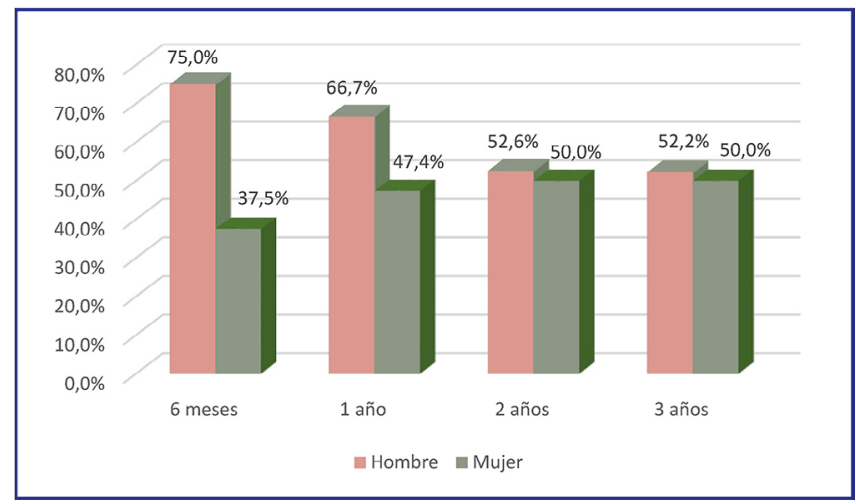

Fuente: elaboración propia.

Gráfico 16. Distribución temporal del empleo encajado del alumnado con discapacidad egresado según sexo.

tación, es el grupo de estudios de Ciencias de la Salud el que muestra el mayor porcentaje $(76,9 \%)$, mientras las Enseñanzas Técnicas apenas alcanzan una cuarta parte de los egresados $(22,2 \%)$.

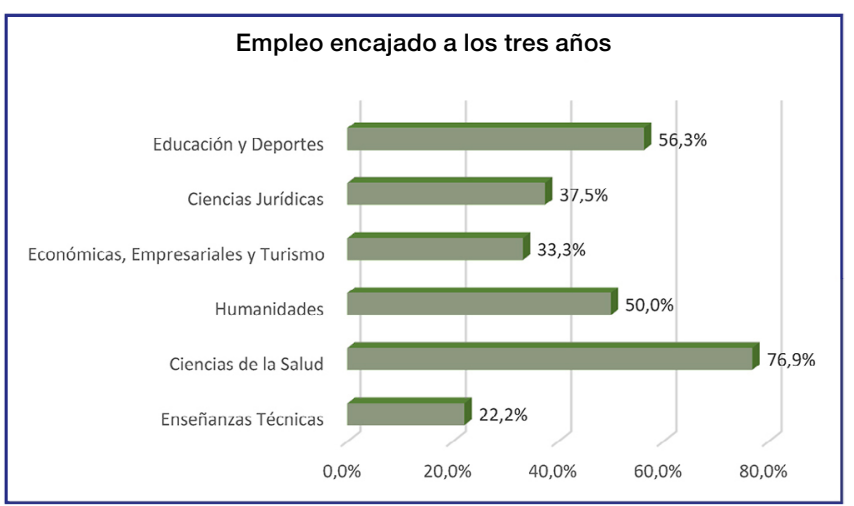

Fuente: elaboración propia.

Gráfico 17. Distribución de empleo encajado del alumnado con discapacidad egresado según grupo de estudios a los 3 años.

\section{DISCUSIÓN Y CONCLUSIONES}

Con este estudio nos propusimos describir y analizar la situación de las personas con discapacidad que han egresado en la ULPGC entre 2000 y 2010. Para analizar la evolución de la situación laboral de los participantes y la calidad del empleo logrado, fue necesario construir una base de datos específica con las trayec- 
torias laborales individuales, lo que fue posible mediante el emparejamiento de los registros académicos de la ULPGC y los datos laborales del OBECAN.

En cuanto a la situación laboral de los egresados, queremos resaltar que la inserción laboral lograda por los egresados de la ULPGC se sitúa en niveles superiores al $20 \%$ a los 6 meses y al $57 \%$ al cabo de tres años, cifra cercana al $62 \%$ de empleados señalado en el estudio de los egresados de la Universidad de Valencia (Fundación Adecco, Fundación Bancaja y Universitat de València, 2012), siendo la discapacidad intelectual la que presenta mayores niveles de colocación a los seis meses y la auditiva a los tres años, lo que coincide con lo apuntado por Cueto, Malo y Rodríguez (2012), Dávila (2006) y Malo (2004).

Respecto al sexo, la inserción femenina es sutilmente mayor que la masculina en todo el periodo, mostrando una diferencia de más de 13 puntos en el segundo ańo, lo que sugiere que la doble discriminación señalada por Dávila (2006) puede no estar afectando a este grupo. En lo relativo al logro de un empleo según los grupos de estudios, los egresados en Humanidades son los que muestran mayores cotas de empleo al tercer año.

En contrapartida se observa que el paro registrado decrece con el tiempo (del $22,3 \%$ al 15,6\%). Las personas con discapacidad auditiva son el grupo con menor paro registrado al quinto año, mientras las mujeres superan a los hombres, lo que coincide con las probabilidades apuntadas por Cueto, Malo y Rodríguez (2012), y quienes cursaron estudios de humanidades suponen el mayor porcentaje de desempleo al quinto ańo desde el egreso de la universidad.

En relación con la calidad del empleo logrado, observando la duración de los contratos, prevalecen los temporales sobre los indefinidos durante todo el periodo analizado, si bien la proporción es algo menor de la que existía en años anteriores en el conjunto del mercado de trabajo español (SEPE, 2013), lo que puede ser un indicador de la relativa mejoría del empleo que se ha producido al finalizar la última crisis económica. Por tipo de discapacidad, la psíquica o intelectual es la que presenta una tasa mayor de temporalidad, tal y como se ha venido observando históricamente (SEPE, 2009); igualmente, la temporalidad afecta más a las mujeres que a los hombres, lo que de algún modo reproduce las condiciones generales del mercado de trabajo y podría estar reflejando cierta forma de discriminación (Dávila, 2006).

En el segundo indicador analizado para valorar la calidad del empleo, el empleo encajado, nuestros resultados muestran niveles en torno al $50 \%$ superior al 30\% de la UNED (Rodríguez de Rivera, 2010) y al 46\% de la Universidad de Valencia (Fundación Adecco, Fundación Bancaja y Universitat de València, 2012); es logrado mayoritariamente por las personas con discapacidad visual, algo mayor entre los hombres y se concentra en el grupo de estudios de Ciencias de la Salud. En conjunto, parece que el logro de un empleo encajado refleja ciertas tendencias generales del mercado de trabajo, particularmente la que apunta a la masculinización de las ocupaciones de mayor nivel en el sector de la salud, y quizás también indique la mayor intensidad de los apoyos que por parte de la ONCE reciben las personas con discapacidad visual.

Estos resultados vienen a ratificar que los egresados con discapacidad de la ULPGC se encuentran dentro de los parámetros recogidos en los informes sobre 
actividad laboral realizados en las últimas décadas. Por tanto, se podría afirmar que los esfuerzos realizados por la ULPGC, en los últimos 15 años, para aplicar las recomendaciones realizadas por los organismos internacionales y nacionales en materia de discapacidad y educación, especialmente el contenido de la legislación española vigente, han contribuido al éxito observado en las trayectorias laborales de los egresados analizadas en este estudio.

Asimismo, cabe destacar que el empleo encajado alcance al 50\% de la población, en tanto que sugiere que la formación universitaria puede contribuir a mejorar la calidad del empleo logrado por las personas con discapacidad. Esto podría estar indicando que la prevalencia de la discapacidad sobre la educación en el momento de acceder a un empleo (Dalmau-Montalé et al., 2013) se podría estar revirtiendo, pues la credencial que supone el título universitario parece que está siendo bien valorada por las empresas que las contratan.

Como se expuso antes, los estudios previos sobre la inserción laboral de personas con discapacidad universitarias son escasos, los disponibles abordan cuestiones generales de la situación de la discapacidad en la universidad, aspectos concretos de la transición al empleo, centrados más en los perfiles de los empleadores y en el tipo de empleo al que se accede; mientras otros analizan algunos aspectos específicos de la inserción laboral del alumnado con discapacidad o la situación general de la población con discapacidad en el mercado de trabajo.

Como consecuencia de ello, surge la necesidad de profundizar en los análisis sobre las trayectorias laborales del alumnado con discapacidad que finaliza con éxito los estudios superiores. En ese sentido, creemos que el presente trabajo aporta una visión novedosa, tanto porque supone uno de los pocos estudios específicos que se han hecho en las universidades españolas como por la metodología usada, ya que no se han encontrado estudios concretos que utilicen el emparejamiento individual como procedimiento de análisis de las trayectorias laborales de las personas con discapacidad universitarias.

En cualquier caso, creemos que este estudio exploratorio aporta una visión general de la situación laboral de las personas con discapacidad tituladas en la ULPGC, que puede tomarse como punto de referencia para realizar comparaciones con los datos que puedan proporcionar otras universidades en el Espacio Europeo de Educación Superior.

Mirando al futuro, por una parte, creemos que otras universidades podrían emular el protocolo de intercambio de datos administrativos que suscribió la ULPGC con el OBECAN, lo que permitiría la construcción de trayectorias laborales individuales y por consiguiente hacer seguimiento de la inserción laboral a medio plazo, para lo que podría ser útil replicar la metodología usada en este trabajo. Por otra parte, consideramos que sería muy interesante realizar estudios en los que participaran diferentes universidades, tanto públicas como privadas, que ofrecieran una visión global de la transición al empleo de los egresados con discapacidad al mismo tiempo que permitirían comparar los niveles de eficiencia y eficacia de las acciones y los servicios de apoyo a la inserción laboral del alumnado con discapacidad. 


\section{REFERENCIAS BIBLIOGRÁFICAS}

Aguilar, M.I. (2005). La inserción laboral de los Jóvenes en España. Un enfoque econométrico. Navarra: Aranzadi Thomson-Civitas.

Albor, J. (2019). Discapacidad: la exclusión social no es solo cosa de pobres. Documento de Trabajo n. ${ }^{\circ} 3.11$. Madrid: Fundación FOESSA, Cáritas Española Editores, recuperado de https://biblioteca. fundaciononce.es/publicacion/descarga/nojs/1497b30b31ee70a673b7d6e296728867. Última consulta: 07/09/20.

ANECA (2009). Los procesos de inserción laboral de los titulados universitarios en España. Factores de facilitación y de obstaculización, recuperado de http://www.aneca.es/Documentos-y-publicaciones/Estudios-de-interes-para-el-ambito-universitario/Los-procesos-de-insercion-laboral-de-los-titulados-universitarios-en-Espana. Última consulta: 10/02/15.

Blázquez, M. y Herrarte, A. (2011). «Cualificación, emparejamiento ocupacional y versatilidad profesional». Economistas, 126: 225-232.

Cabra de Luna, M. (2004). «Discapacidad y aspectos sociales la igualdad de oportunidades, la no discriminación y la accesibilidad universal como ejes de una nueva política a favor de las personas con discapacidad y sus familias. Algunas consideraciones en materia de protección social». Revista del Ministerio de Trabajo y Asuntos Sociales, 50: 21-46.

Colectivo IOÉ (2003). «La inserción laboral de las personas con discapacidades». Barcelona: Fundación La Caixa, recuperado de https://www.colectivoioe.org/index.php/publicaciones_libros/ show/id/46. Última consulta: 20/04/20.

Cueto, B., Malo, M.A. y Rodríguez, V. (2012). «La brecha de la participación laboral de las personas con discapacidad en España. Un análisis con la EDAD-2008». Cuadernos del Mercado de Trabajo, 8: 26-33.

Dalmau-Montalá, M. et al., (2010). Integración laboral de los universitarios españoles con discapacidad. Detección de las fortalezas y debilidades en el momento del acceso al mercado laboral español. Percepción de los universitarios y percepción de las empresas. Fundación Universia y Universidad Ramon Llull, recuperado de https://www.fundacionuniversia.net/wp-content/ uploads/2016/04/Integracion_Laboral_Universitarios_Discapacidad_RamonLlull.pdf. Última consulta: 17/08/2020.

Dalmau-Montalá, M. et al. (2013). "Formación universitaria e inserción laboral. Titulados espańoles con discapacidad y competencias profesionalizadoras». Revista Española de Discapacidad, I (2): 95-118. http://dx.doi.org/10.5569/2340-5104.01.02.06.

DÁvila, C.D. (2006). «Discapacidad y género: Un estudio de participación en el mercado de trabajo español». Moneda y Crédito, 223, 127-158.

De Lorenzo, R. (2003). El futuro de las personas con discapacidad en el mundo. Desarrollo humano y Discapacidad. Madrid: Fundación ONCE y Ediciones del Umbral.

Díaz-Velázquez, E. (2011). «Estratificación y Desigualdad por motivo de Discapacidad». Intersticios: Revista Sociológica de Pensamiento Crítico, 5(1): 157-170.

Fundación Adecco, Fundación Bancaja y Universitat de Valencia (2012). «La integración laboral de universitarios con discapacidad. Informe de investigación 2012", recuperado de http//www.fundacionbancaja.es/archivos/publicaciones/informe_integracion_discapacidad.pdf. Última consulta: 10/03/16. 
Fundación ONCE y ILO Business and Disability Network (2019). Making the future of work inclusive of people with disabilities, recuperado de https://biblioteca.fundaciononce.es/publicaciones/colecciones-propias/programa-operativo/making-future-work-inclusive-people. Última consulta: 16/08/2020.

Fundación Universia (2016). «Universidad y discapacidad. III Estudio sobre el grado de inclusión del sistema universitario español respecto de la realidad de la discapacidad», recuperado de: http://riberdis.cedd.net. Última consulta: 10/03/17.

Fundación Universia (2017). «Universidad y discapacidad. III Estudio sobre el grado de inclusión del sistema universitario español respecto de la realidad de la discapacidad", recuperado de http:// riberdis.cedd.net. Última consulta: 10/03/17.

Fundación Universia (2018). «Universidad y discapacidad. IV Estudio sobre el grado de inclusión del sistema universitario español respecto de la realidad de la discapacidad», recuperado de http:// riberdis.cedd.net. Última consulta: 10/03/17.

FUNDACIÓN UNIVERSIA y CERMI (2012). «Estudio sobre el grado de inclusión del sistema universitario español respecto de la realidad de la discapacidad», recuperado de https://sid.usal.es/idocs/F8/ FDO26384/inclusion_universidad.pdf. Última consulta: 18/08/2020.

Fundación Universia y CERMI (2014). «Universidad y Discapacidad. II Estudio sobre el grado de inclusión del sistema universitario español respecto de la realidad de la discapacidad», recuperado de http://riberdis.cedd.net. Última consulta: 10/03/17.

Guasch, D. (dir.) (2010). Estudio sectorial por comunidades autónomas de la accesibilidad del entorno universitario y su percepción. Barcelona: Observatorio Universidad y Discapacidad (entidad formada por Fundación ONCE y la Universidad Politécnica de Cataluña-Barcelona Tech), recuperado de https://www.uva.es/export/sites/uva/6.vidauniversitaria/6.11.accesibilidadarquitectonica/_documentos/Observatorio-Universidad-y-Discapacidad-09.pdf. Última consulta:16/08/20.

Huete García, A. (2013). «La exclusión de la población con discapacidad en España. Estudio específico a partir de la Encuesta Social Europea». Revista Española de Discapacidad, I (2): 7-24. http://dx.doi.org/10.5569/2340-5104.01.02.01.

Malo, M.A. (2003). «Las personas con discapacidad en el mercado de trabajo español». Revista del Ministerio de Trabajo e Inmigración, (46): 99-126.

Malo, M.A. (2004). «¿Cómo afectan las discapacidades a la probabilidad de ser activo en Espańa?». Cuadernos de Economía, 27(74): 75-108.

Malo, M.A. (dir.), Cueto, B., Dávila, C.D., Pagán, R. y Rodríguez, V. (2010). Evaluación de la politica de bonificaciones y reducciones de cuotas de la Seguridad Social destinada a Personas con Discapacidad. Madrid: Ministerio de la Presidencia. Agencia Estatal de Evaluación de las Políticas Públicas y la calidad de servicios, recuperado de http://www.aeval.es/es/ difusion_y_comunicacion/publicaciones/Informes/Informes_de_Evaluacion/Evaluaciones_2009/E19.html. Última consulta: 26/08/2020.

Malo, M.A. y Muñoz-Bullón, F. (2006). «Employment promotion measures and the quality of the job for persons with disabilities». Hacienda Pública Española/Revista de Economía Pública, 179(4): 79-111.

Observatorio estatal de la Discapacidad (2010). "Las personas con discapacidad en España. Informe Olivenza 2010", recuperado de http://riberdis.cedd.net. Última consulta: 26/01/15. 
Observatorio estatal de la Discapacidad (2014). "Las personas con discapacidad en España. Informe Olivenza 2014", recuperado de http://riberdis.cedd.net. Última consulta: 26/01/15.

Observatorio estatal de la Discapacidad (2015). «Las personas con discapacidad en España. Informe Olivenza 2016», recuperado de http://riberdis.cedd.net. Última consulta: $13 / 01 / 2016$.

Observatorio estatal de la Discapacidad (2016). "Las personas con discapacidad en España. Informe Olivenza 2016", recuperado de http://riberdis.cedd.net. Última consulta:13/03/2017.

Observatorio estatal de la Discapacidad (2017). «Las personas con discapacidad en España. Informe Olivenza 2018", recuperado de http://riberdis.cedd.net. Última consulta:13/05/2018.

Observatorio estatal de la Discapacidad (2018). «Las personas con discapacidad en España. Informe Olivenza 2018», recuperado de https://www.observatoriodeladiscapacidad.info/ category/documentos/observatorio/informe-olivenza-observatorio. Última consulta: 26/08/20.

Observatorio estatal de la Discapacidad (2019). «Las personas con discapacidad en España. Informe Olivenza 2018», recuperado de https://www.observatoriodeladiscapacidad.info/ category/documentos/observatorio/informe-olivenza-observatorio. Ultima consulta: 26/08/20.

ODISMET (2020). Integración Laboral y Mercado de Trabajo. Datos 2018, recuperado de https:// www.odismet.es/banco-de-datos/1integracion-laboral-y-tendencias-del-mercado-de-trabajo. Última consulta: 26/08/20.

OIT (1983). Convenio 159 (OIT), de 22 de junio de 1983, sobre la readaptación profesional y el empleo de personas inválidas, recuperado de https://www.ilo.org/dyn/normlex/es/f?p=NORMLEXPUB:12100:0::NO::P12100_ILO_CODE:C159. Última consulta: 26/08/20.

OIT (2001). Repertorio de recomendaciones prácticas sobre la gestión de discapacidades en el lugar de trabajo, recuperado de https://www.ilo.org/public/spanish/standards/relm/gb/docs/ gb282/pdf/tmemdw-2.pdf. Última consulta: 16/08/20.

OIT (2015). La importancia del empleo y los medios de vida en la agenda para el desarrollo con posterioridad a 2015. Nota conceptual de la OIT sobre la agenda de desarrollo post 2015, recuperado de https://www.ilo.org/wcmsp5/groups/public/---dgreports/---dcomm/documents/statement/wcms_206443.pdf. Última consulta: 16/08/2020.

OIT (2020). Discapacidad y Trabajo, recuperado de https://www.ilo.org/global/topics/disability-and-work/WCMS_475652/lang--es/index.htm. Última consulta: 26/08/20.

OMS (2020). 10 Datos sobre la Discapacidad, recuperado de https://www.who.int/features/factfiles/ disability/es/. Última consulta: 26/08/20.

Pallisera, M. et al. (2003). "La integración laboral de personas con discapacidad en la empresa ordinaria en España aproximación a través de una investigación». Siglo Cero, 34(208): 5-18.

Red2Red Consultores (2013). Discapacidad, estudios superiores y mercado de trabajo. Barreras de acceso y repercusión en la inserción laboral. Madrid: Fundación ONCE y Fondo Social Europeo, recuperado de https://www.fundaciononce.es/sites/default/files/Discapacidad_estudios_superiores.pdf. Última consulta: 26/08/20.

Rodríguez de Rivera, I. (2010). «Informe sobre el desarrollo profesional de egresados y estudiantes con discapacidad en la UNED». Centro de atención a universitarios con discapacidad (UNIDIS). Madrid: UNED-Fundación Mapfre.

SEPE (2009). Informe del Mercado de Trabajo de las PCD Estatal. Datos 2008. Madrid: Servicio Público de Empleo Estatal. Observatorio de Ocupaciones, recuperado de https://www. 
sepe.es/HomeSepe/que-es-el-sepe/observatorio/informes-mercado-trabajo/informes-anuales-mercado-trabajo-estatal/ver-resultados.html?documentType=informes\&tipo=1\&periodo=anual\&ambito=Nacional. Última consulta: 26/08/20.

SEPE (2013). Informe del Mercado de Trabajo de las PCD Estatal. Datos 2012. Madrid: Servicio Público de Empleo Estatal. Observatorio de Ocupaciones, recuperado de https://www. sepe.es/HomeSepe/que-es-el-sepe/observatorio/informes-mercado-trabajo/informes-anuales-mercado-trabajo-estatal/ver-resultados.html?documentType=informes\&tipo=1\&periodo=anual\&ambito=Nacional. Última consulta: 26/08/20. 